\title{
Sistem Informasi Verifikasi Dan Validasi Pendaftaran Ujian Komprehensif Berbasis Android (Studi Kasus Ilmu Komputer Di Universitas Bina Darma)
}

\author{
Randa Firnando \& Novri Hadinata \\ Fakultas Teknik Ilmu Komputer, Universitas Bina Darma \\ Email: randafirnando111@gmail.com
}

\begin{abstract}
An android-based comprehensive exam registration verification and validation information system. Registration for a comprehensive exam is a requirement that must be done by students to conduct a comprehensive trial. The problems of this research are (1) How to design a comprehensive online registration information system based on Android? (2) How to make a comprehensive online registration information system application. The objectives of this study are (1) to produce a comprehensive online registration information system design (2) to produce an android-based comprehensive registration information system application. A website-based comprehensive exam registration verification and validation information system to improve services in comprehensive registration. This system is built using the Model Prototype methodology, modeling Unified Modeling Language, Java programming language, Android Studio framework, and SMBD MySQL. This research resulted in the application of an Androidbased comprehensive exam registration verification and validation information system that can be utilized by the Bina Darma University in the process of students who will carry out a comprehensive trial.
\end{abstract}

Keywords: information system, online trial registration system, website

\section{Pendahuluan}

Perkembangan teknologi informasi pada masa sekarang ini sudah semakin pesat dan maju, salah satunya adalah adanya internet, hingga saat ini hampir disegala bidang membutuhkan internet sebagai sumber informasi dan telekomunikasi yang cepat dan efisien. Penggunaan internet saat ini

sudah menjadi suatu kebutuhan umum yang sangat penting bagi seluruh lapisan penjuru masyarakat, dimulai dari anak-anak sampai orang dewasa menggunakan internet sebagai media informasi. Dengan demikian, pemakaian internet dibidangsistem informasi memberikan manfaat yang sangat besar seperti penyajian informasi yang dibutuhkan dapat diperoleh secara cepat tanpa memerlukan proses pencarian yang rumit.

Ujian komprehensif adalah ujian yang dilaksanakan untuk mengetahui tingkat kemampuan pemahaman dan penguasaan teoritik mahasiswa secara menyeluruh terhadap materi perkuliahan yang telah diberikan. Ujian ini diikuti oleh mahasiswa setelah menyelesaikan semua mata kuliah dan praktikum.

Sistem pendaftaran ujian komprehensif pada fakultas ilmu komputer di Universitas Bina Darma, Setiap mahasiswa pasti akan melalui yang namanya proses akademik, mulai dari siswa tersebut ditetapkan sebagai mahasiswa sampai menyelesaikan studi. Dalam proses penyelesaian studi / tugas akhir / skripsi terdapat beberapa ujian di fakultas ilmu komputer universitas bina darmayaitu ujian komprehensif / ujian skripsi. Ujian komprehensif adalah ujian yang diadakan untuk menguji wawasan mahasiswa. Pendaftaran ujian komprehensif fakultas ilmu Komputer.

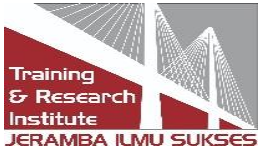


Tulisan yang dapat dimuat adalah yang mengkaji masalah yang berhubungan dengan teknologi dibidang mesin, elektronika dan ilmu komputer.

Pendaftaran ujian komprehensif yang ada di fakultas Pendaftaran ujian komprehensif fakultas ilmukomputer dilakukan melalui link google form :https://forms.gle/yqUgyeMuDQxiQp6Y8 oleh masing-masing mahasiswa. Data yang telah diinput mahasiswatidak bisa diedit, oleh sebab itu sebelum dilakukan submit data harus diteliti terlebih dahulu. Apabila mahasiswa telah berhasil melakukan pendaftaran melalui google form maka akan tampil menu upload berkas dengan kelengkapan berkas yang sudah di tentukan Setelah mahasiswa melalukan pendaftaran ujian komprehensif melalui google form maka pihak admin atau ppm(pusat pelayanan mahasiswa) akan melakukan verifikasi dan validasi untuk melakukan pengecekan dokumen yang telah di ajukan mahasiswa melalui google form untuk pengambilan keputusan. Jika salah satu dokumen mahasiswa belum lengkap pihak admin atau ppm(pusat pelayanan mahasiswa) akan di memberitahukan kepada mahasiswa melalui email bahwa persyaratan ujian komprehensif belum lengkap.

Penelitian ini berisi masalah pada sistem yang telah ada, yaitu kurang terintegrasinya data terkait pendaftaran ujian komprehensif, pelaporan yang masih dikerjakan secara manual, dan databasing yang kurang sistematis. Solusi dari permasalahan yang ada adalah dengan implementasi sebagai metodologi dalam analisis, perancangan dan pemrograman sistem pendaftaran sidang komprehensif mulai dari pendaftaran ujian komprehensif, pelaksanaan ujian komprehensif. Tujuan penelitian ini adalah untuk menghasilkan implementasi pada aplikasi sistem pendaftaran sidang komprehensif yang diharapkan menjadisolusi dari keterbatasan-keterbatasan sistem yang ada. Simpulan dari penelitian ini adalah bahwa aplikasi pendaftaran ujian komprehensif menggunakan metode Prototype memiliki banyak keunggulan, diantaranya adalah sifat reusability program, maintenance yang tidak rumit, dan mudah untuk dikembangkan untuk keperluan yang akan bagi Universitas Bina Darma Palembang.

Kepesatan teknologi yang telah sampai pada era kepadatan informasi menuntut setiap pihak pemilik informasi untuk mengelola informasi mereka secara integratif dan sistematis. Sehingga data menjadi aman, mudak dipakai dandapat diolah secara efektif dan efisien. Untuk menghasilkan pengelolaan data pada sistem yang mudah dan handal, maka diperlukan suatu aplikasi yang menjadi penghubung sekaligus pengatur pengelolaan data dan informasi tersebut terkait pendaftaran komprehensif, maka penulis memberikan solusi yaitu sebuah Sistem Informasi Verifikasi dan Validasi Pendaftaran Ujian Komprehensif Berbasis Android dimana apikasi ini memberikan kemudahan dalam proses pendaftaran ujian komprehensif. Dengan adanya sistem yang di dukung adanya basis data sehingga membuat informasi lebih konsisten ketika sewaktu-waktu dibutuhkan maka informasi dapat di akses dengan mudah dan cepat. Sistem ini dikembangkan guna membantu petugas pendaftaran melakukanperekapan data lebih cepat dalam melakukan proses verifikasi data dan validasi pendafataran ujian komprehensif bagi mahasiswa

yang telah melakukan pendaftaran dan mempermudah mahasiswa untuk mendapat kan informasi pendaftaran komprehensif.

\section{Tinjauan Literatur}

\subsection{Internet}

Published by:

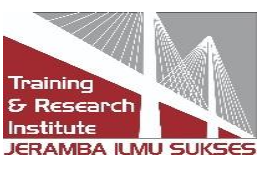


Internet (interconnection-networking) adalah suatu jaringan informasi dan komunikasi global melalui suatu protokol yang disebut Transmission Control Protocol / Internet Protocol Suite (TCP/IP). TCP/IP digunakan sebagai protocol pertukaran paket (packet switching communication protocol) untuk melayani miliaran pengguna di seluruh dunia. Rangkaian internet yang terbesar dinamakan Internet. Cara menghubungkan rangkaian dengan kaidahini dinamakaninternetworking (Christianto dan Wiryana, 2002).

\subsection{Aplikasi Android}

Aplikasi adalah program yang dibuat oleh pemakai yang diajukanuntukmelakukan tugas khusus. Program seperti ini biasa dikelompokan menjadi dua, yaitu program aplikasi serbaguna dan program aplikasi spesifik [1]. Aplikasi android ditulis dalam bahasa pemrograman java. Kode java dikompilasi bersama dengan data file resource yang dibutuhkan oleh aplikasi, dimana prosesnya di package oleh tools yang dinamakan apt tools kedalam paket android sehingga menghasilkan filedengan ekstensi .apk. File apk itulah yang disebut dengan aplikasi, dan nantinya dapat di install diperangkat mobile (Putra, Nugroho and Nugroho, 2014)

\subsection{Android}

Android adalah sistem operasi untuk telepon seluler yang berbasis Linux. Android menyediakan platform yang bersifat open source bagi para pengembang untuk menciptakan sebuah aplikasi (Suhas Holla danMahima M. Katti, 2012) Awalnya, Google Inc. mengakuisi Android Inc. yang mengembangkan software untuk ponsel yang berada di Palo Alto, California Amerika Serikat. Kemudian untuk mengembangkan Android,dibentuklah Open Handset Alliance, yaitu konsorsium dari 34 perusahaan hardware, software, dan telekomunikasi, termasuk Google, HTC, Intel, Motorola, Qualcomm, T- Mobile, dan Nvidia. Teleponpertamayang memakai sistem operasi Android adalah HTC Dream,yang dirilis pada 22 Oktober 2008. Pada penghujung tahun 2009 diperkirakan di dunia ini paling sedikit terdapat 18 jenis telepon seluler yang menggunakan Android (Burd, 2014).

\subsection{UML (Unified Modelling Language)}

Menurut Rossa \& Shalahudin (2018) UML (Unified Modelling Language)adalah salah satu standar bahasa yang banyak digunakan digunakan di dunia industri untuk mendefinisikan requirement, membuat analisis \& desain, serta menggambarkan arsitektur dalam pemograman berorientasi objek.

\subsection{SDK (Android Software DevelopmentKit)}

Android SDK merupakan tools yang digunakan dalam mengembangkanaplikasi mobile yang berbasis sistem operasi android. Android SDK dapat dijalan kanpada sistem operasi linux dan sistem operasi windows (Putra 2016).

\subsection{Sistem Informasi}

Menurut Jogiyanto (2005), sistem informasi adalah suatu sistem di dalam suatu organisasi yang mempertemukan kebutuhan pengolahan transaksi harian, mendukung operasi, bersifat manajerial dan kegiatan strategidari suatu organisasi dan menyediakan pihak luartertentu dengan laporan- laporan yang diperlukan.

\subsection{PHP (PHP: Hypertext Preprocessor)}

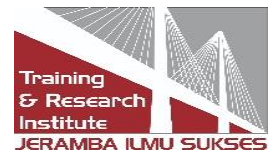


PHP pertama kali dibuat oleh Rasmus Lerdroft, seorang programmer C. Pada waktu itu PHP masih bernama FI (Form Interpreted), yang wujudnya berupasekumpulan script yang digunakanuntuk mengolah data form dari web.Jadi semula PHP digunakannya untuk menghitung jumlah pengunjung di dalam webnya.

PHP sendiri sebenarnya merupakan singkatan dari "Hypertext Preprocessor", yang merupakan sebuah bahasa scripting tingkat tinggi yang dipasang pada dokumen HTML. Sebagian besar sintaks dalam PHP mirip dengan bahasa C, Java dan Perl, namun pada PHP ada beberapa fungsi yang lebih spesifik. Sedangkan tujuan utama dari penggunaan bahasa ini adalah untuk memungkinkan perancang web yang dinamis dan dapat bekerja secara otomatis.

\section{$2.8 \mathrm{Java}$}

Java menurut definisi Sun adalah bahasa berorientasi objek yang dapat digunakan untuk pengembangan aplikasi mandiri, aplikasi berbasis internet, serta aplikasi untuk perangkatperangkat cerdas yang dapat berkomunikasi

lewat internet atau jaringan komunikasi. Dalam Java ada 2 (dua) jenisprogramberbeda, yaitu aplikasi dan applet. Aplikasi adalah program yang bisaanya disimpan dan dieksekusi dari komputer lokal sedangkan applet adalah program yang bisaanya disimpan pada komputer yang jauh, yangdikoneksikan pemakai lewat web browser(Burd, 2014).

\section{9 metode prototype}

Metode Prototype merupakan metode pengembangan perangkat lunak yangmemungkinkan adanya interaksi antara pengembang sistem dengan pengguna sistem, sehingga dapat mengatasi ketidakserasian antara pengembang dan pengguna (Pressman, 2012: 50).

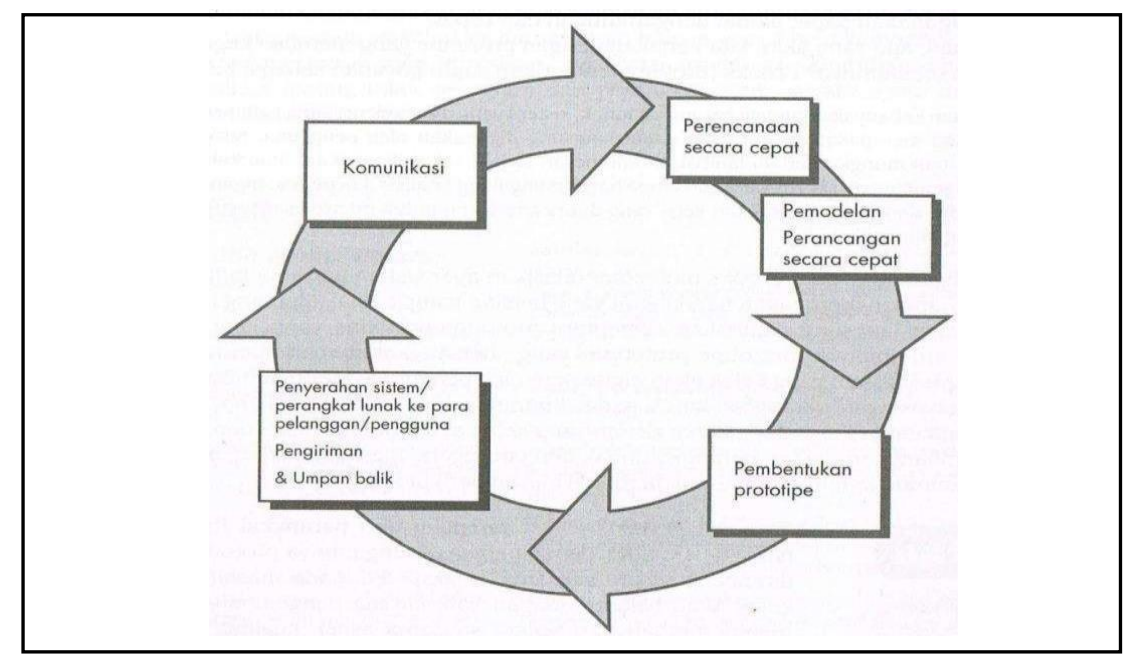

Gambar 2.1Metode Prototype (Sumber: Roger S. Pressman, 2012:50)

Seringkali pelanggan mendefinisikan sejumlah sasaran perangkat lunak secara umum, tetapi tiak bisa mengidentifikasispesifikasi kebutuhanyang rinci untuk fungsifungsi dan fitur-fitur yang nantinya akan dimiliki perangkat lunak yang akan dikembangkan. Dalam kasus yang lain, pengembangan perangkat lunakmungkin merasa tidak pasti tentang efisiensi suatu algoritma yang akan digunakan dalam

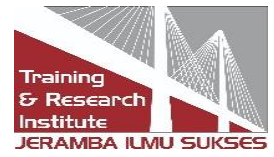


pengembangan perangkat lunak, atau juga merasa tidak pasti akan kemampuan perangkat lunak untuk beradaftasi dengan manusia-komputer yang digunakan. Dalam kasus-kasus seperti ini dan dalam banayak situasi yang lain, paradigm pembuatan prototype (prototyping) mungkin menawarkan pendekatanyang paling baik (Pressman, 2012:50).

Dimulai dengan dilakukannya komunikasi antara tim pengembang perangkat lunak dengan pada pelanggan. Tim perangkat lunak akan melakukan petemuan- pertemuan dengan stakeholder untuk mendefinisikan sasaran keseluruhan untuk perangkat lunak yang akan dikembangkan, mengidentifikasi spesifikasi kebutuhan apapun yang saat ini diketahui, dan menggambarkan area-area dimanadidefinisilebih jauh pada iterasi selanjutnyamerupakan keharusan (Antoni, Fikari \& Akbar, 2018; Antoni \& Akbar, 2019; Antoni, Jie \& Abareshi, 2020; Antoni, Herdiansyah, Akbar \& Sumitro, 2021).

Iterasi pembuatan prototype direncanakan dengan cepat dan pemodelan (alam bentuk "rancangan cepat") dilakukan. Suatu rancangan cepat berfokus padarepresentasi semua aspek perangkatlunak yang akan terlihat oleh para pengguna akhir (misalnya rancangan antar muka pengguna [user interface] atau format tampilan). Rancangan cepat (quick design) akan memulai kontribusi pembuatan prototype. prototypek emudian akan diserahkan kepada para stakeholder dan kemudian mereka akan melakukan evaluasi-evaluasi tertentu terhadap prototype yang telah dibuat sebelumnya, kemudian akhirnya akan memberikan umpan- balikyang akan digunakan untuk memperhalus spesifikasi kebutuhan. Iterasi akan terjadi saat prototype iperbaiki untuk memenuhi kebutuhan dari para stakeholder, sementara pada saat yang sama memungkinkan kita untuk lebih memahami kebutuhan apa yang akan dikerjakan pada iterasi selanjutnya (Pressman, 2012:51-52)

Idealnya, prototype bertindak sebagai mekanisme untuk mengidentifikasi sesifikasispesifikasi kebutuhan perangkat lunak. Jika suatu prototype yang dapatdigunakan akan dikembangkan, kita bisa menggunakan program yang sudah adasebelumnya atau dengan menerapkan penggunaan perangkat yang sudah ada (misalnyaperangkat pembentuk laporan [refort generator] atau aplikasi untuk melakukan perancangan antarmuka [window manager) yang memungkinkanprogram yang dapat digunakan dapat dibuat dengan mudah dan cepat (Pressman,2012:52).

\section{Metode Penelitian}

\subsection{Metode Pengumpulan Data}

\section{1) Tinjauan Pustaka (Library Research)}

Dalam metode ini penulis Mencari informasi menggunakan jurnal yang sudah ada serta website yang ada sehingga mendukung dalam pengumpulan data yang berhubungan dengan permasalahan yang diambil dalam penulisan laporan ini (Fauzi, Dencik \& Asiati, 2019).

\section{2) Wawancara (Interview)}

Untuk mendapatkan data-data secara langsung dari sumber yang berkaitan daalam penelitian ini dengan pengamatan yang dilakukan penulis. Dalam hal ini penulis mengajukan pertanyaanpertanyaankepada PPM (pusat pelayanan mahsiswa ) Di Universitas Bina Darma Palembang.

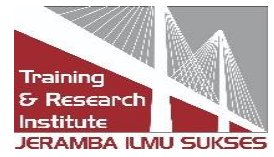




\subsection{Metode Pengembangan Aplikasi}

Dalam penulisan penelitian ini penulis menggunakan metodologi Metode Prototype. menurut Pressman, 2012: 50 metode prototype merupakan metode pengembangan perangkat lunak yang memungkinkan adanya interaksi antara pengembang sistem dengan pengguna sistem, sehingga dapat mengatasi ketidakserasian antara pengembang dan pengguna.

a. Proses bisnis yang berjalan

Menganalisis sistem yang sedang berjalan bertujuan untuk mengetahui lebih jelas bagaimana cara kerja sistem tersebut dan masalah yang dihadapi sistem untuk dijalankan landasan usulan perancangan sistem. Berdasarkan pengamatan yang penulis lakukan.

Pendaftaran ujian komprehensif pada fakultas ilmu komputer terbagimenjadi beberapa proses yang dilakukan berdasarkan urutan. Adapun analisis prosedur proses pendaftaran komprehensif yang sedang berjalan tersebut.

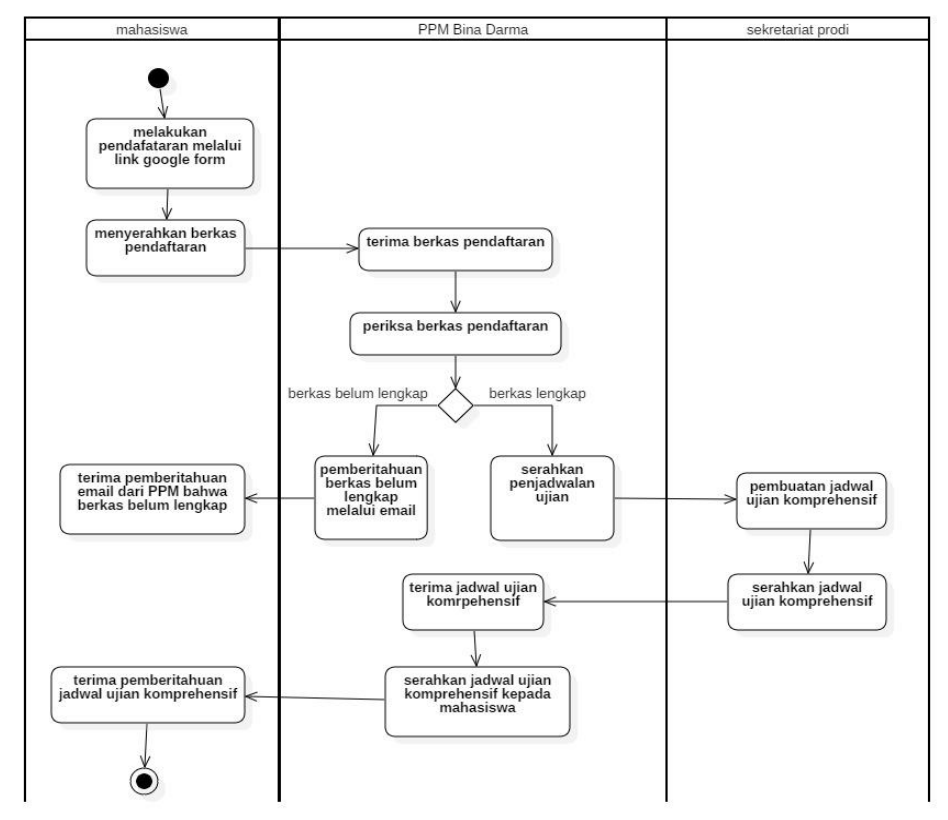

Gambar 1. Proses bisnis yang berjalan

Setelah dilakukan analisis sistem yang berlaku, secara garis besar ditarik kesimpulan bahawa secara fungsional sistem yang berjalandapat memenuhi tujuan meskipun masih terdapat beberapa kekurangan yang harus diperbaiki dan ditingkatkan lagi. Kelemahankelemahan yang ada pada sistem yang berjalan antara lain:

1) Sistem penyimpanan data pada sistem yang sedang berjalan masihsecara terpisahpisah, masing-masing memiliki file penyimpanan sendiri sehingga sistem yang berjalan tidak efisien.

2) Kurangnya integrasi sistem distribusi data mahasiswa yang mendaftar seminar / ujian komprehensif sehingga menyebabkan keterlabatan dalam hal administrasi.

Dari deskripsi sistem yang sedang berjalan di atas, terlihat masih adanya proses

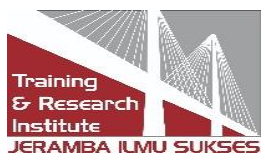


pengolahan data yang dilakukan secara manual,sehingga lambatnya proses penjadwalan seminar/ujian komprehensif, serta kurang terstrukturnya pengolahan data penjadwalan seminar / ujian komprehensif pada fakultas ilmu komputer.

b. Proses bisnis yang diusulkan

Pendaftaran ujian komprehensif pada fakultas ilmu komputer terbagimenjadi beberapa proses yang dilakukan berdasarkan urutan. Adapun gambaran proses bisnis yang di ajukan.

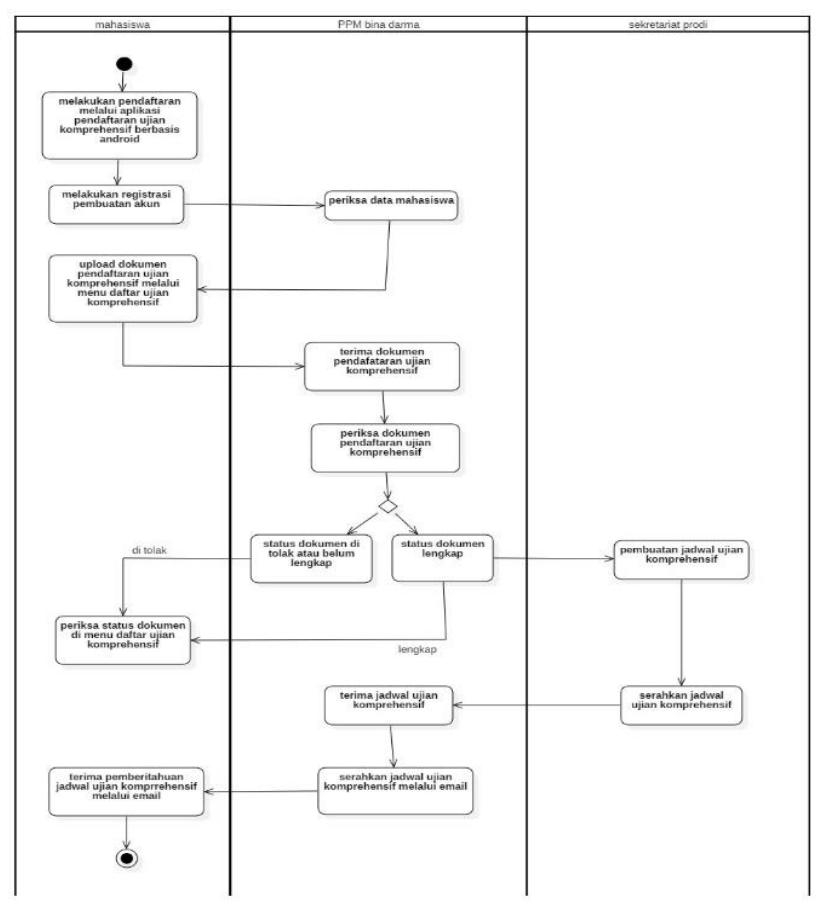

Gambar 2. Proses bisnis yang diusulkan

\section{Hasil dan Pembahasan}

\subsection{Hasil}

Setelah melakukan kegiatan desain dan rekayasa sistem yang telah dibahas sebelumnya, maka hasil yang di peroleh adalah sebuah sistem informasi verifikasi dan validasi pendaftaran ujian komprehensif berbasis android ini merupakan aplikasi yang sudah di buat berdasarkan hasil rancangan pada bab sebelumnya sistem informasi verifikasi dan validasi pendaftaran ujian komprehensif berbasis android dimana sistem ini berfungsi sebagai pendaftaran ujian komprehensif secara online yang terdiri 2 user yaitu admin, mahasiswa,

\subsection{Pembahasan}

Pembangunan aplikasi system informasi verifikasi dan validasipendaftaran ujian komprehensif ini menggunakan Bahasa pemograman $p h p$ dan database mysql. Untuk mendapatkan hasil dari apa yang telah di lakukan pada tahap rancangan program yang telah di lakukan sebelumnya, maka pada pembahasan ini akan di tampilkan tampilan-tampilan dari keseluruhan system. Berikut tampilan-tampilan yang ada di system. 


\section{a. Tampilan judul}

Tampilan judul merupakan tampilan pertama saat pengguna membukaaplikasi, tampilan judul pada umumnya menampilkan judul dari aplikas yang dibuka dan diberi waktu beberapa saat untuk menampilkanjudul tersebut kemudian baru masuk pada tampilan utama dari aplikasi.

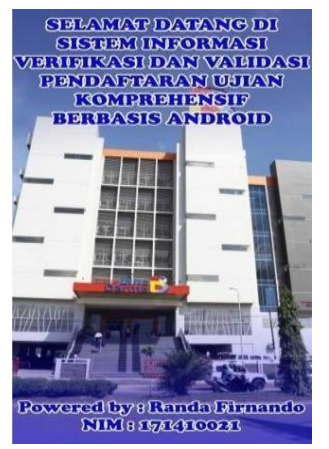

Gambar 3. tampilan judul

b Tampilan login mahasiswa

Tampilan login mahasiswa yang berfungsi untuk melakukan validasi ke aplikasi android, dengan mengisikan form username dan password lalu memilih button masuk, Jika belum memiliki akun maka silahkan klik button Registrasi.

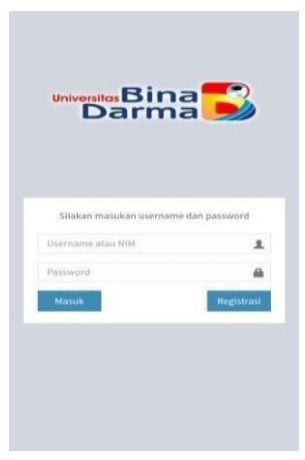

Gambar 4. tampilan login amahasiswa 


\section{c. Tampilan rigistrasi}

pada halaman registrasi yang berfungsi untuk pendaftaran mahasiswa sebagai pengguna aplikasi, dengan mengisikan NIM, Username, Prodi, Jenis kelamin, password lalu pilih button DAFTAR.

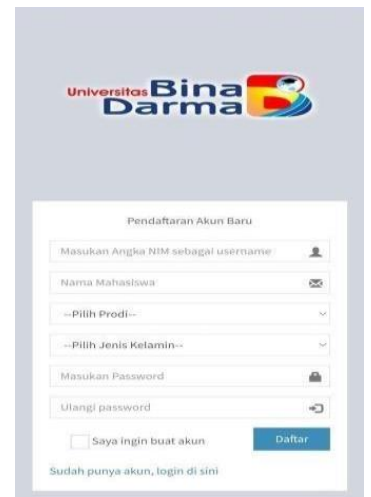

gambar 5. Tampilan registrasi

d. Tampilan Dashboard

Tampilan Dashboard merupakan halaman yang menampilkan sebuah informasi dari pihak Universitas Bina Darma.

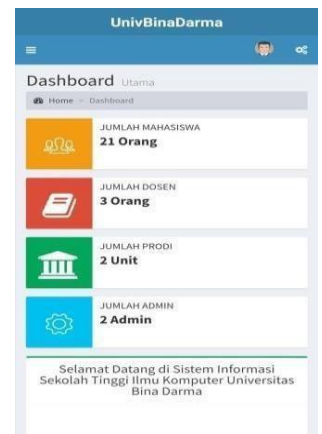

Gambar 6. Tampilan dashboard

e. Tampilan Upload Dokumen

Tampilan Upload Dokumen merupakan halaman yang menampilkan daftar dokumen yang akan di upload oleh mahasiswa dengan syarat yang telah di tentukan .

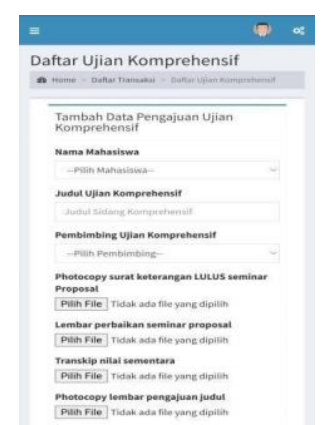

Gambar 7. halaman upload dokumen

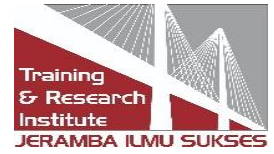




\section{f. Tampilan profil}

Tampilan profil menampilkan informasi user yang meliputi data NIM,Nama mahasiswa, prodi, dan jenis kelamin.

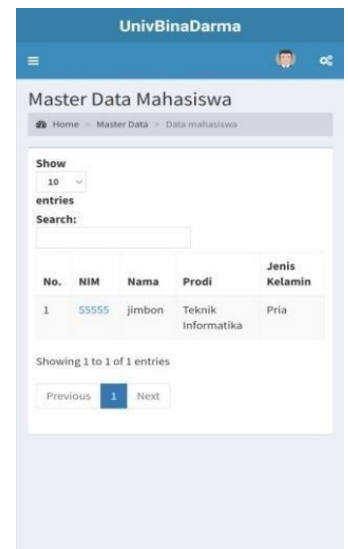

Gambar 8. Tampilan profil

g. Tampilan status dokumen

tampilan Status dokumen berfungsi untuk menampilkan status mahasiswa setelah upload dokumen apakah telah di setujui atau belum disetujui.

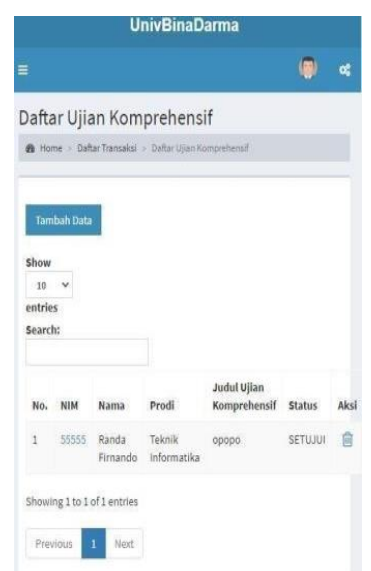

Gambar 9. Tampilan status dokumen

\section{Kesimpulan}

Berdasarkan hasil penelitian dan pembahasan yang telah di lakukan pada system informasi verifikasi dan validasi pendaftaran ujian komprehensif berbasis android, maka dapat di simpulkan sebagai berikut;

a. pada penelitian ini menghasilkan system informasi verifikasi dan validasipendaftaran ujian komprehensif berbasis android dimana system ini berfungsi sebagai pendaftaran ujian komprehensif secara online yang terdiri 4 user yaitu admin, mahasiswa, kaprodi sIstem infomasi dan kaprodi Teknik informatika.

b. Bahasa pemograman yang di gunakan dalam membangun system yaitu menggunakan Bahasa pemograman PHP dan basisdata MYSQL

c. Dengan danya system ini untuk Mempermudah mahasiswamendapatkan infromasi

Published by:

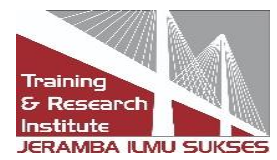




\section{(蠗 JPSII

komprehensif secara cepat dan akurat

\section{Referensi}

A. S., Rosa dan Shalahuddin, M. 2018. Rekayasa Perangkat LunakTerstruktur danBerorientasi Objek. Bandung: Informatik

Adi Putra Nugraha, 2009. Aplikasi Pemesanan Makanan Berbasis Android padaRumah Makan “ Lek Nonong”. Skripsi . Universitas Diponegoro.

Antoni, D., \& Akbar, M. (2019). E-supply chain management value concept for the palm oil industry. Jurnal Sistem Informasi, 15(2), 15-29.

Antoni, D., Fikari, D., \& Akbar, M. (2018). The readiness of palm oil industry in enterprise resource planning. Telkomnika, 16(6), 2692-2702.

Antoni, D., Herdiansyah, M. I., Akbar, M., \& Sumitro, A. (2021). Pengembangan Infrastruktur Jaringan Untuk Meningkatkan Pelayanan Publik di Kota Palembang. JURNAL MEDIA INFORMATIKA BUDIDARMA, 5(4), 1652-1659.

Antoni, D., Jie, F., \& Abareshi, A. (2020). Critical factors in information technology capability for enhancing firm's environmental performance: case of Indonesian ICT sector. International Journal of Agile Systems and Management, 13(2), 159-181.

Burd, Barry. Java Programming for Android Developers for Dummies. New Jersey:John Wiley \& Sons, Inc., 2014.

Christianto, V dan I Made Wiryana. Manajemen Proyek Berbasis Internet.

Fauzi, F., Dencik, A. B., \& Asiati, D. I. (2019). Metodologi Penelitian untuk manajemen dan akuntansi. Jakarta: Salemba Empat.

Jakarta:PT. Elex Media Komputindo, 2002.

Jogiyanto, HM., 2005. Analisis dan Disain Sistem Informasi, ANDI, Yogyakarta.

Moleong, L.J. (2011). Metodologi Penelitian Kualitatif Edisi Revisi. Bandung:

PT.Remaja Rosdakarya.

Pressman, Roger, S. 2012. Rekayasa Perangkat Lunak.Pendekatan Praktisi. Edisi 7. Yogyakarta : Andi

Sidik, Betha. Pemrograman Web dengan PHP7. Bandung: Informatika, 2017.

Sutanta, Edhy. Pengantar Teknologi Informasi. Yogyakarta, 2005.

\section{Copyrights}

Copyright for this article is retained by the author(s), with first publication rights granted to the journal.

This is an open-access article distributed under the terms and conditions of the Creative Commons Attribution license (http://creativecommons.org/licenses/by/4.0/) 